\title{
UK 1-D regional velocity models by analysis of variance of P-wave travel times from local earthquakes
}

\author{
David C. Booth \\ British Geological Survey, Murchison House, West Mains Road, \\ Edinburgh EH9 3LA, UK. E-mail: dcb@bgs.ac.uk
}

\begin{abstract}
A method is presented for deriving 1-D velocity depth models from earthquake bulletin data. The models can be used as initial models for more advanced modelling techniques such as tomographic inversion. The method is useful when there is little or no refraction and long-range reflection survey data. The bulletin travel times are subjected to an analysis of variance, where they are separated into source, distance, and receiving station terms. The distance terms describe the variation of travel time with distance, and the associated trend lines allow 1-D velocity models for the crustal layers to be determined. The velocity models provide an average crustal model for the region derived from local data. This does not include superficial layers which are necessarily poorly determined. Earthquake bulletin P-wave data from propagation paths across three different regions of the UK are employed to illustrate the use of the technique.
\end{abstract}

Key Words:

P-waves, velocity models, statistical methods 


\section{INTRODUCTION}

The determination of a seismic velocity structure for a region is essential for accurate location of earthquakes and other seismic events, through the estimation of reliable wave travel times, and provides information on structural boundaries for geological and geophysical interpretations, usually with a depth resolution which is not possible for other geophysical exploration methods. Current methods (e.g. Thurber 1983, 1987; Kissling, 1988, Kissling et al. 1994) use as much reliable information as possible from seismic bulletins, refraction and reflection profiles, and other sources of data, to form a tomographic velocity model derived from wavepaths sampling as much of the crust and upper mantle volume under the region as possible. Tomographic inversion techniques require a starting model for the inversion. This is often composed of one or more 1-D velocity-depth models, and for optimum results the 1-D models should be close approximations to the average local structure in the area of interest. Such models are usually derived from seismic refraction and long-range reflection profiles, where seismic phases are recorded over measured distances with accurate timing of the source event and the arrival time of the seismic waves along the profile. A velocity-depth model can then be constructed to match the observed variation of travel-time with distance.

Very few refraction and reflection seismic profiles have been performed on land in the UK and most of the information on crustal velocity structure in the onshore UK has come from the Lithospheric Seismic Profile in Britain (LISPB) (Bamford et al. 1978; Barton 1992) and the Caledonian Suture Seismic Experiment (Bott et al. 1985). Away from these lines, few models are available, and many of them are only over a shallow depth range. The British Geological Survey (BGS) uses various regional 1-D seismic velocity models for earthquake location, which were derived mainly from the refraction surveys of Bamford et al. (1978), Bott et al. (1985), and Havskov \& Bungum (1987). Chadwick \& Pharaoh (1998) and Clegg \& England (2003) have produced Moho depth maps from reflection and refraction data, although resolution of the depth contours onshore is necessarily poor since little data exists. Refraction profiles onshore are very expensive; timing and charge size problems have not allowed the use of quarry blasts as effective explosion sources to use with the fixed UK seismic monitoring network. Earthquakes provide a high energy seismic source, but the event origin time and hypocentre are not accurately known to permit the derivation of the velocity structure along the wavepath.

In this work, I employ an analysis of variance (AoV) technique to determine a travel time-distance curve and station corrections for P-wave travel times from a large number of earthquakes recorded at UK short-period seismic stations in the range $0-300 \mathrm{~km}$. The technique was originally applied by Carpenter et al. (1967) to the amplitude attenuation with distance of teleseismic P-waves, but the method is equally applicable to the variation with distance of seismic travel-times. In contrast to most inversion procedures, a good a priori starting model is not required. It allows a travel-time distance relation to be deduced from earthquake data, without the necessity of accurate timing of the event origin time. In this paper this technique is tested by using travel times measured in different regions of the UK, obtained from P-wave arrival times in the Bulletins of British 
Earthquakes, for example Galloway (2008), which are published annually by the BGS.

\section{METHOD OF ANALYSIS}

Scheffé (1959) defined analysis of variance as 'a statistical technique for analysing measurements depending on several kinds of effects operating simultaneously to decide which kinds of effects are important and to estimate the effects'. The technique was originally devised by Fisher (1925) and has been further developed since then by Scheffé (1959), Kempthorne (1952), Brownlee (1965) and others. Carpenter et al. (1967) used the AoV method to determine amplitude variation with distance, and source size and station attenuation, from recorded amplitudes of teleseismic P-waves. In this paper Carpenter et al.'s (1967) technique is applied to local P-wave travel times.

If many earthquakes are recorded at different stations at different distances, it is possible to perform an analysis of variance of the travel time data to determine the variation of travel time with distance, and source and station terms which correspond to relative contributions to the overall travel times in the vicinity of the source and of the seismometer station. Hence an average variation of travel time with distance can be derived from which to estimate the average velocity structure for a region.

Following Carpenter et al. (1967), I write the P-wave travel time measured at a station as

$T=b+s+r+c$

where the overall travel time is separated into a distance term $r$, associated with the epicentral distance, a source term $b$ which allows for variation in source depth and inaccuracy in the determination of the origin time, a station term $s$ which allows for local velocity variation in the immediate vicinity of the station, and a constant $c$. The reason for introducing the constant term will be made clear below. The full range of distances over which the measurements are made is subdivided into a number of shorter consecutive distance ranges. For convenience these are made of equal length, though this is not a necessary condition.

To analyse the data I follow Carpenter et al. (1967) and make the assumption that if $\mathrm{T}_{i j k}$ is the measured $\mathrm{P}$-wave travel time from the source of earthquake $i$ to station $j$ whose epicentral distance lies in the $k$-th distance range then

$T_{i j k}=b_{i}+s_{j}+r_{k}+c+e_{i j k}$

where $b_{i}$ is the source term for the $i$-th earthquake, $s_{j}$ is the station term for the $j$-th station, $r_{k}$ is the distance term for the $k$-th distance range, $c$ is constant, and $e_{i j k}$ is an error. Every measured travel time can be expressed as a summation of the appropriate source, station and distance term values. The values of $b_{i}, s_{j}, r_{k}$ and $c$ can be estimated in the presence of the error $e_{i j k}$ by the method of least squares (on the assumption that the errors have zero mean) with the conditions

$\Sigma b_{i}=\Sigma s_{j}=\Sigma r_{k}=0$, 
where $b_{i}$ are summed over all earthquakes, $s_{j}$ are summed over all stations, and $r_{k}$ are summed over all distance ranges. Condition (3) is applicable due to the linear dependence of the terms in equation (2), and introduction of the constant $c$ permits the application of this condition. The average values of $b_{i}, s_{j}$ and $r_{k}$ are set to zero and their true values become a matter of definition. The values of $b_{i}, s_{j}$ and $r_{k}$ are found by matrix inversion, and the elements of the inverse matrix are used to calculate the confidence limits for $b_{i}, s_{j}$, and $r_{k}$, through making the additional assumption that the errors $e_{i j k}$ are normally distributed. The problem corresponds to an analysis of variance of three effects - source, distance and station - on the measured travel times.

To obtain the travel times from the P-wave arrival time data in the bulletins, it is necessary to use a velocity model to derive earthquake origin times and hypocentre locations. A single velocity model was used rather than the different regional velocity models which are usually used for location, to avoid the results being biased by the regional models. The results are compared with the location model to show that the derived 1-D models are different from it.

\section{DATA}

The P-wave arrival times were taken from the BGS Bulletins of British Earthquakes $1990-2008$ which are published using data primarily from the BGS UK seismic monitoring network, with data from stations in Norway and Ireland sometimes being used for events offshore. The bulletins publish P- and S- wave arrival times measured from station seismograms and the location and origin time of each earthquake, estimated by the HYPO71 earthquake location algorithm which obtains a best fitting solution in terms of location and origin time for the observed travel times applied to a 1-D velocity-depth model for the region of the earthquake (Lee \& Lahr 1975). While normally BGS uses 1-D regional models for locating earthquakes, in the present study locations and origin times were calculated using a simple two-layer velocity-depth model in case the regional models bias the solution. Only two layers were used in case the introduction of arbitrary crustal layers also introduced a bias. The model consists of a $6.5 \mathrm{~km} \mathrm{~s}^{-1}$ P-velocity crust of thickness $34.15 \mathrm{~km}$ over a lower halfspace of P-velocity 8.0 $\mathrm{km} \mathrm{s}^{-1}$. The crustal velocity was chosen as an average value based on the regional velocity models described in section 1 , and the crustal thickness corresponds to the Moho depth of the most commonly used regional model (Galloway 2008). It is possible to grade the location quality of each earthquake according to the number of wave arrival readings used for the solution, the widest gap angle subtended between stations, and the RMS residual. Bulletin readings were only used if four or more readings were available, the gap angle was $180^{\circ}$ or smaller, and the RMS residual was less than 0.4 . The UK station network is relatively dense and usually only the data from stations within $150 \mathrm{~km}$ of the event are used in location determination. The P-wave travel-times used here were obtained by subtracting the estimated origin time from the P-wave arrival times for each station. Epicentral distance values are used for the analysis. Data from earthquake swarm sequences (e.g. Stoke on Trent 1995, Newcastle under Lyme 1997, Manchester 2002, Aberfoyle 2003, Eskdalemuir 2004) were limited to one or two representative earthquakes, usually the largest in the sequence. Seismometer 
stations contributing ten bulletin measurements or more were used for the analysis.

I have analysed P-wave travel-times measured in three different areas of the UK. One dataset consists of P-wave travel times measured at stations in Scotland for earthquakes in the Central and West Scotland (CWS) region, and another is derived from earthquakes in Scotland and England recorded by stations in Southern Scotland and Northern England, which is called the Border region. The third dataset contains travel times for events in Central England recorded by stations in England and Wales. The propagation paths for the three datasets are shown in Figure $1(\mathrm{a}-\mathrm{c})$, and the corresponding P-wave travel time - distance variation for all observations in each of the three datasets is plotted in Figure 2(ac).

In each analysis of variance study, the entire distance range was divided into $10 \mathrm{~km}$ sections. The analysis produced source and station terms for each source and station, and distance terms for each section where one or more stations provided travel time data. The derived constant $c$ in equation 1 was added to each distance term to give a distance term equivalent to the average travel time for each range. The statistical values, distance and station terms, and 95\% confidence limits resulting from the analysis are listed in Tables 1, 2 and 3 respectively. Each average travel time is associated with a distance range, but the distances may not be evenly spread within that range, and so when plotting the distance term it can be misleading to associate it with the midpoint of the range. Hence the mean distance for all observations within each $10 \mathrm{~km}$ distance range has been calculated, and the mean distances are shown in Table 2. The distance terms (average travel times) for each region are plotted for mean distance values in Figure 3(a-c), and also in Figure 2(a-c), where they are superimposed on the set of observations from which they are derived.

To estimate crustal velocities, the travel time-distance plots are divided into sections where the variation shows a linear variation with constant slope, and the resulting trend lines associated with a least squares fit to these sections are drawn. If we assume there is a 1-D velocity structure of horizontal homogeneous plane layers of different velocities, standard formulae can be used to calculate the velocity of the lowest layer and the thickness and velocity of each layer above it using the slope and intercept of each trend line (for example Kearey \& Brooks, 1984). The velocity of the uppermost layer will be poorly constrained as few first arriving $\mathrm{P}$-waves propagate only in that layer. The source term will provide a disproportionately large contribution to the overall travel time at short distances of $30 \mathrm{~km}$ and less, and so the distance terms do not provide useful information on the velocity in the superficial layers. Independent information is necessary to constrain the average velocity in the top few kilometres, which determines the thickness of the top layer and the depth of the lower layers.

\section{RESULTS}

\subsection{Central and West Scotland}

The distance term plots and associated trend lines are shown for the CWS region in Figure 3(a). These indicate that the average crustal velocity structure shows at least two layers over an upper mantle of velocity $8.0 \mathrm{~km} \mathrm{~s}^{-1}$ (Figure 4), and is thus 
different from the simple two-layer model which was used to provide the earthquake locations. The velocities of the crustal layers are $6.3 \mathrm{~km} \mathrm{~s}^{-1}$ and $6.9 \mathrm{~km}$

$\mathrm{s}^{-1}$. The intercepts on the distance axis indicate layer thicknesses of 13.3 and 16.7 $\mathrm{km}$ respectively giving an overall crustal thickness of $30.0 \mathrm{~km}$. The zero intercept of the $6.3 \mathrm{~km} \mathrm{~s}^{-1}$ trend line suggests that a low velocity surface layer is absent or very thin. A recent 3-D model for NW Europe indicates a $30-35 \mathrm{~km}$ thick crust under most of mainland Britain (Kelly et al. 2007). The Moho is deeper than 35 $\mathrm{km}$ under east central Scotland but this area is poorly sampled by the bulletin data due to low seismicity. It is seen in Figure 2(a) that there is most scatter in the travel times in the range $160-200 \mathrm{~km}$, where the Pn phase has overtaken the lower crustal phase. This may be partly attributable to the variation in strength of the Pn arrival for different earthquakes over this distance range, due to the variation in focal mechanisms. At larger distance ranges, clear P-wave onsets are few and only available for the largest earthquakes. Bott (2001, pers. comm.) applied a joint hypocentre-velocity inversion to a smaller dataset covering a slightly wider area than CWS. Using an initial 4-layer model, Bott determined a 1D structure of 6.3 and $6.9 \mathrm{~km} \mathrm{~s}^{-1}$ at the depths of 7.5 and $19 \mathrm{~km}$ specified in the starting model, with the Moho at $34 \mathrm{~km}$ above an $8.1 \mathrm{~km} \mathrm{~s}^{-1}$ upper mantle; the results derived here are consistent with these.

Teleseismic receiver function data (Tomlinson et al., 2006) indicate that over the area in which the stations are located, the Moho depths vary between $25 \mathrm{~km}$ at RRR and $36 \mathrm{~km}$ at PGB, and there are significant differences between the 1D receiver function models at RRR, MCD, KPL, and KAR. Tomlinson et al. (2006) note that there are significant differences between the crustal thicknesses derived from the receiver functions and those derived from refraction studies, and suggest that in some places the phases originally considered to result from Moho conversion correspond rather to conversions from the top of the high velocity layer at the base of the crust. It is more appropriate to compare the analysis of variance results with crustal thicknesses derived from refraction studies rather than receiver function studies.

\subsection{Border region}

The distance terms and trend lines are shown in Figure $3 \mathrm{~b}$ and the resulting velocity-depth model is shown in Figure 4. Again the scatter in the range 160-200 $\mathrm{km}$ is associated with the intercept of the Pn and lower crustal phases. Assuming an average top layer velocity of $5.8 \mathrm{~km} \mathrm{~s}^{-1}$ (Jacob 1969), the model is as shown in Fig.4. The trend lines indicate a three-layer crust, with layer thicknesses 0.4, 7.3, and $22.2 \mathrm{~km}$ and corresponding velocities 5.8, 6.3 and $6.7 \mathrm{~km} \mathrm{~s}^{-1}$ over an upper mantle of velocity $8.4 \mathrm{~km} \mathrm{~s}^{-1}$. The non-zero intercept which the trend line corresponding to $6.3 \mathrm{~km} \mathrm{~s}^{-1}$ makes with the travel time axis in Figure $3 \mathrm{~b}$ indicates the presence of a shallow low velocity surface layer. As described in Section 3, the velocity in shallow surface layers is poorly constrained by the distance terms; independent information is necessary to constrain the average velocity in the top few kilometres. Refraction profiles in the Borders region indicate velocities of from 5.5 to $6.0 \mathrm{~km} \mathrm{~s}^{-1}$ in the uppermost crust (Jacob 1969, Bamford et al. 1978, Bott et al. 1985, Barton 1992), and a poorly constrained average value of $5.8 \mathrm{~km}$ $\mathrm{s}^{-1}$ has been used for the velocity of the surface layer.

The north-south oriented LISPB profile (Bamford et al. 1978) and a NE-SW oriented CSSP profile in Northern England (Bott et al. 1985) cross the Border 
region. The LISPB model of Barton (1992) in the Border region indicates a midcrustal refractor of $6.8 \mathrm{~km} \mathrm{~s}^{-1}$, of thickness $13 \mathrm{~km}$ under a basement layer of thickness $\sim 20 \mathrm{~km}$ which has a velocity gradient from $5.7 \mathrm{~km} \mathrm{~s}^{-1}$ to $6.2 \mathrm{~km} \mathrm{~s}^{-1}$.

The velocities derived for this upper crustal layer by Barton (1992) are lower than the velocity of $6.3 \mathrm{~km} \mathrm{~s}^{-1}$ at $4 \mathrm{~km}$ depth derived by a Southern Upland Seismic Profile (SUSP, Hall et al. 1983), which was at right angles to the LISPB profile. The results also differ from the structure deduced by Bott et al. (1985) from the CSSP profile crossing Northern England. Bott et al. (1985) detected a welldefined $6.15 \mathrm{~km} \mathrm{~s}^{-1}$ basement at 2-4 $\mathrm{km}$ with a well-defined mid-crustal refractor of velocity about $6.6 \mathrm{~km} \mathrm{~s}^{-1}$ starting at $16-18 \mathrm{~km}$ depth. However the structure deduced in the present study can only be an average, and diversity in structure is clearly indicated from these previous results in the Border area.

\subsection{Central England}

The variation of the distance terms with distance in Figure 2c was fitted with linear trend lines as shown in Figure $3 \mathrm{c}$. Beyond $200 \mathrm{~km}$ there are relatively few data values, resulting in the larger errors seen at this distance range. An average surface layer velocity of $4.8 \mathrm{~km} \mathrm{~s}^{-1}$ was taken as the independent assessment required to constrain the depth of the surface layer, based on the laterally heterogeneous structure in this region suggested by Whitcombe and Maguire (1980). The trend lines in Figure 3c indicate a refractor of velocity $8.2 \mathrm{~km} \mathrm{~s}^{-1}$, under a $22.4 \mathrm{~km}$ thick layer of velocity $6.5 \mathrm{~km} \mathrm{~s}^{-1}$, a $4.7 \mathrm{~km}$ thick layer of velocity $6.4 \mathrm{~km} \mathrm{~s}^{-1}$, and a surface layer of thickness $0.5 \mathrm{~km}$. Few refraction profiles have been carried out in central and southern England. Whitcombe and Maguire (1980) have tentatively identified a basement refractor at $2 \mathrm{~km}$ depth with a P-wave velocity of $6.4 \mathrm{~km} \mathrm{~s}^{-1}$ near station CWF.

\subsection{Station Terms}

The station terms listed in Table 2 do not show any trends in spatial distribution that can be detected and appear to be due to very local site differences. Where the same stations provide bulletin records that have been used for the Central and West Scotland region and the Border region, the terms are similar within estimation error, even though the wavepaths are different. Most stations closer than $10 \mathrm{~km}$ show similar terms, allowing for estimation error, but at some nearby stations, station terms can differ significantly even when a large number of wavepaths are averaged (for example, at the stations EDI and ESY, 25km apart), clearly illustrating the existence of local differences in velocity structure, which is likely to be common throughout the UK.

\section{CONCLUSIONS}

The distance terms obtained by analysis of variance of the travel times obtained from bulletin data describe the variation of travel time with distance and they can be used to derive an average velocity structure for the crustal region through which the waves propagate. The layer velocities, thicknesses and crustal depths are consistent with those derived from refraction surveys. The method produces average $1 \mathrm{D}$ velocity models for the crustal layers. The velocity and thickness of a 
superficial layer must be determined independently as it rarely provides a quantifiable contribution to the body wave travel times.

The analysis of variance of body wave travel-times from earthquake bulletin data separates the travel time data into source, distance and receiver contributions, so that inaccuracy in the earthquake origin time is removed from the distance contribution to wave travel times. The distance terms describe the variation of travel time with distance and they can be used to derive an average velocity structure for the crustal region through which the waves propagate. The layer velocities, thicknesses and crustal depths are reasonably consistent with those derived from refraction surveys. However, it is difficult to compare them with those derived from receiver function analysis, since in some areas it appears that the phases in receiver function data which are thought to result from Moho conversion are likely to be conversions from the top of the high velocity layer at the base of the crust. The method produces average 1D velocity models for the crustal layers. However the velocity of superficial layers must be determined independently as they rarely provide a quantifiable contribution to the body wave travel times. The method is useful for providing an average velocity structure in areas where long range refraction survey data is not available. This can be used as a reliable starting model for analysis by more advanced analytical techniques such as seismic tomography.

\section{ACKNOWLEDGEMENTS}

I thank Professor Alan Douglas for suggesting that the AoV method be applied to seismic travel times, and Alan and his colleague Mr John Young (both then at AWE) for supplying the analysis of variance program used in this study. I also thank Brian Baptie and Lars Ottemöller, who supplied the location data and useful advice, and two anonymous reviewers whose suggestions helped to improve the paper. This paper is published with the permission of the Executive Director of the British Geological Survey (NERC).

\section{REFERENCES}

Barton, PJ (1992) LISPB revisited: a new look under the Caledonides of Northern Britain. Geophys J Int 110: 371-391.

Bamford D, Nunn K, Prodehl C, Jacob B (1978) LISPB-IV. Crustal structure of northern Britain. Geophys J R Astr Soc 54: 43-60.

Bott MHP, Long RE, Green, AS P, Lewis AH J, Sinha MC, Stevenson DL (1985) Crustal structure south of the Iapetus Suture beneath northern England. Nature 314:724-727.

Brownlee KA (1965) Statistical theory and Methodology in Science and Engineering, 2nd ed., Wiley, New York.

Carpenter EW, Marshall PD, Douglas A, (1967) The amplitude-distance curve for short period teleseismic P-waves. Geophys J R Astr Soc:13, 61-70.

Chadwick RA, Pharaoh TC (1998) The seismic reflection Moho beneath the United Kingdom and adjacent areas. Tectonophys:299, 255-279. 
Clegg B, England RW (2003) Velocity structure of the UK continental shelf from a compilation of wide-angle and refraction data. Geol Magazine:140, 453-467.

Fisher RA (1925) Statistical methods for research workers. Hafner, New York.

Hall J, Powell DW, Warner MR, El-Isa ZH, Adesanya O, Bluck BJ (1983) Seismological evidence for shallow crystalline basement in the Southern Uplands of Scotland. Nature:305, 418-420.

Havskov J, Bungum H (1987) Source parameters for earthquakes in the North Sea. Norsk Geologisk Tidsskrift: 67, 51-58.

Galloway DD (ed.) (2008) Bulletin of British earthquakes 2007. British Geological Survey Technical Report OR/08/048.

Jacob AWB (1969) Crustal phase velocities observed at the Eskdalemuir seismic array. Geophys J R Astr Soc:18, 189-197.

Kearey P, Brooks M. (1984) An Introduction to Geophysical Exploration. Blackwell, Oxford

Kelly A, England RW, Maguire PKH (2007) A crustal seismic velocity model for the UK, Ireland and surrounding seas. Geophys J Int: 171, 1172-1184.

Kempthorne O (1952) Design of experiments. Wiley, New York.

Kissling E (1988) Geotomography with local earthquake data. Rev Geophys:26, 659-698.

Kissling E, Ellsworth WL, Eberhart-Phillips, D, Kradolfer U (1994) Initial reference models in local earthquake tomography. J Geophys Res:99, 1963519646.

Lee W, Lahr J (1975) HYPO71 (revised). A computer program for determining hypocenter, magnitude and first motion pattern of local earthquakes. Open File Rep US Geol Survey 75.

Scheffé H (1959) The Analysis of Variance. John Wiley. London.

Thurber, CH (1983) Earthquake locations and three-dimensional crustal structure in the Coyote Late area, central California. J Geophys Res:88, 8226-8236.

Thurber, CH (1987) Analysis methods of kinematic data from local earthquakes. Rev Geophys:24, 793-805.

Tomlinson JP, Denton P, Maguire PKH, Booth DC (2006) Analysis of the crustal structure of the British Isles using teleseismic receiver functions. Geophys J Int 167: 223-237.

Whitcombe DN, Maguire PKH (1980) An analysis of velocity structure of the Precambrian rocks of Charnwood Forest. Geophys J R Astr Soc 63: 405-416. 


\section{FIGURE CAPTIONS}

Figure 1(a). Map showing propagation paths between earthquakes (black dots) and UK seismometer stations (triangles), corresponding to the seismograms used in the analysis of variance study for Central and West Scotland.

Figure 1(b). as Figure 1(a), for the Border region.

Figure 1(c). as Figure 1(a), for Central England.

Figure 2(a) Distance terms (open diamonds) obtained from analysis of variance of observed P-wave travel times from bulletin data (black diamonds) for propagation paths in Central and West Scotland.

Figure 2(b). As Figure 2(a), for recorded P-wave travel times in the Border region from earthquakes shown in Figure 1(b).

Figure 2(c). As Figure 2(a), for recorded P-wave travel-times in Central England from earthquakes shown in Figure 1(c).

Figure 3(a) Distance terms obtained from analysis of variance of P-wave travel times for propagation paths in Central and West Scotland, showing 95\% confidence limits (crosses) and linear trendlines.

Figure 3(b). As Figure 3(a), for recorded P-wave travel-times in the Border region.

Figure 3(c). As Figure 3(a), for recorded P-wave travel-times in Central England.

\section{TABLE CAPTIONS}

Table 1 Statistics associated with analysis of variance of the distance and station terms

Table 2. Distance terms with $95 \%$ confidence limits. Note that errors depend on the number $(\mathrm{N})$ of records available for each distance range.

Table 3. Station terms with $95 \%$ confidence limits. Note that errors depend on the number $(\mathrm{N})$ of station records available. 
Table 1. Statistics associated with analysis of variance of the distance and station terms

$\begin{array}{llll} & \text { CWS } & \text { Border } & \text { C. England } \\ \text { Variance of a Single Observation } & 0.225 & 0.244 & 0.266 \\ \text { Total Degrees of Freedom } & 2131 & 2005 & 1121 \\ \text { Total degrees of freedom for distance ranges } & 24 & 26 & 25 \\ \text { Average square attributable to distance effect } & 1442.6 & 1136.4 & 1086.3 \\ \text { Significance } & <0.1 \% & <0.1 \% & <0.1 \% \\ & & & \\ \text { Total degrees of freedom for stations } & 34 & 30 & 16 \\ \text { Average square attributable to station effect } & 1.229 & 1.303 & 0.773 \\ \text { Significance } & <0.1 \% & <0.1 \% & <0.1 \% \\ \text { Constant } & 19.88 & 20.51 & 19.82\end{array}$


Table 2. Distance terms with 95\% confidence limits. Note that errors depend on the number $(\mathrm{N})$ of records available for each distance range.

\begin{tabular}{|c|c|c|c|c|c|c|c|c|c|c|c|}
\hline \multicolumn{4}{|c|}{ Central \& W. Scotland } & \multicolumn{4}{|c|}{ Border } & \multicolumn{4}{|c|}{ Central England } \\
\hline $\begin{array}{l}\text { Dist. } \\
(\mathrm{km})\end{array}$ & $\begin{array}{l}\text { Term } \\
\text { (sec) }\end{array}$ & rror & $\mathbf{N}$ & $\begin{array}{l}\text { Dist. } \\
(\mathbf{k m})\end{array}$ & $\begin{array}{l}\text { Term } \\
\text { (sec) }\end{array}$ & Error & $\mathbf{N}$ & $\begin{array}{l}\text { Dist. } \\
\text { (km) }\end{array}$ & $\begin{array}{l}\text { Term } \\
\text { (sec) }\end{array}$ & Error & $\mathbf{N}$ \\
\hline 6.5 & 0. & \pm 0.16 & 65 & 1 & 1 & 8 & 83 & 1 & 2 & 8 & 9 \\
\hline 15.6 & 2.37 & \pm 0.13 & 263 & 15.8 & 2.50 & \pm 0.16 & 170 & 5 & 2.87 & 0.20 & 48 \\
\hline 25.2 & 3.93 & \pm 0.12 & 262 & 25.7 & 4.04 & \pm 0.15 & 256 & 25.5 & 4.10 & \pm 0.16 & 103 \\
\hline 36.4 & 5.71 & \pm 0.12 & 490 & 35 & 5.46 & \pm 0.15 & 390 & 36.1 & 5.81 & \pm 0.16 & 98 \\
\hline 4 & 6.96 & 2 & 38 & 44.3 & 6 & \pm & 267 & 5 & 7 & 5 & 142 \\
\hline 54.7 & 8.58 & 1 & 309 & 55.5 & 0 & 5 & 258 & 5.2 & 8.75 & 15 & 157 \\
\hline 64.7 & 10.12 & \pm 0.12 & 182 & 64.8 & 10.26 & \pm 0.15 & 251 & 65.3 & 10.30 & \pm 0.14 & 173 \\
\hline 75 & 11.76 & \pm 0.12 & 176 & 74.4 & 11.74 & \pm 0.15 & 217 & 74.8 & 11.81 & \pm 0.15 & 134 \\
\hline 84.9 & 13.40 & \pm 0.14 & 89 & 84.8 & 9 & \pm & 110 & 84.6 & 13.34 & \pm 0.16 & 103 \\
\hline 94.8 & 1 & \pm 0.13 & 111 & 95 & 3 & \pm 0.17 & 88 & 95 & 15.02 & \pm & 95 \\
\hline 105.2 & 16.6 & \pm 0.15 & 62 & 104.6 & 7 & $\pm C$ & 68 & 04.9 & 16.50 & \pm & 99 \\
\hline 15.4 & 18.25 & \pm 0.14 & 86 & 114.8 & 18.02 & \pm 0.18 & 63 & 115.5 & 18.18 & \pm 0.17 & 75 \\
\hline 125.1 & 19.80 & \pm 0.15 & 63 & 125.1 & 19.68 & \pm 0.19 & 48 & 125.1 & 19.69 & \pm 0.21 & 35 \\
\hline 134.9 & 21.20 & \pm 0.17 & 46 & 135.1 & 3 & \pm 0.21 & 34 & 134.5 & 21.08 & \pm & 35 \\
\hline 145.6 & 2 & & 51 & 1 & & & 2 & ; & & & O \\
\hline 55.3 & 24.36 & \pm & 26 & 154.1 & 1 & \pm 0 & 18 & 52.8 & 3 & \pm & 2 \\
\hline 164.3 & 25.32 & \pm 0.23 & 21 & 163.9 & 25.09 & \pm 0.29 & 13 & 163.6 & 25.12 & \pm 0.29 & 15 \\
\hline 175.8 & 27.17 & \pm 0.24 & 22 & 176.2 & 26.85 & \pm 0.34 & 10 & 173.6 & 26.92 & \pm 0.48 & 5 \\
\hline 183.8 & 27.69 & \pm 0 & 11 & 182.8 & 72 & 33 & 10 & 184.8 & 27.92 & .44 & 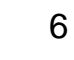 \\
\hline 2.5 & 29. & 67 & 2 & 196.6 & 0 & \pm 0.37 & 8 & 190.5 & 4 & \pm 0.7 & 2 \\
\hline 205.5 & 30.5 & \pm 0.45 & 5 & 204.9 & 29.91 & \pm 0.47 & 5 & 202 & 29.67 & \pm 1.1 & $\perp$ \\
\hline 219.6 & 32.60 & \pm 0.93 & 1 & 215.8 & 31.50 & \pm 0.52 & 4 & 215.6 & 31.56 & \pm 0.53 & 4 \\
\hline 276.4 & 40.19 & \pm 0.96 & 1 & 228.3 & .74 & \pm 1.01 & 1 & 228.3 & 33.05 & \pm 1.05 & 1 \\
\hline 280.4 & 39.96 & \pm 0.98 & 1 & 246 & 35.05 & \pm 1.01 & 1 & 238 & 34.79 & \pm 0.74 & 2 \\
\hline 05.1 & 42.71 & \pm 0.71 & 2 & 255.3 & .08 & \pm 0.77 & 2 & 48.8 & 36.07 & \pm 1.03 & 1 \\
\hline & & & & 271.4 & 3 & \pm 1.25 & 1 & 269.6 & 38.13 & \pm 1.03 & 1 \\
\hline & & & & 287.5 & 39.88 & 0.81 & 2 & & & & \\
\hline
\end{tabular}


Table 3. Station terms with $95 \%$ confidence limits. Note that errors depend on the number $(\mathrm{N})$ of station records available.

Central \& W. Scotland

\begin{tabular}{|c|c|c|c|c|c|c|c|c|c|c|c|}
\hline Stn. & $\begin{array}{l}\text { Term } \\
\text { (sec) }\end{array}$ & Error & $\mathbf{N}$ & Stn. & $\begin{array}{l}\text { Term } \\
\text { (sec) }\end{array}$ & Error & $\mathbf{N}$ & Stn. & $\begin{array}{l}\text { Term } \\
\text { (sec) }\end{array}$ & Error & $\mathbf{N}$ \\
\hline $\mathrm{BHH}$ & 0.11 & \pm 0.27 & 15 & $\mathrm{BBH}$ & -0.10 & \pm 0.11 & 93 & HPK & -0.02 & \pm 0.13 & 75 \\
\hline BWH & -0.17 & \pm 0.27 & 13 & BBO & -0.07 & \pm 0.10 & 107 & LMK & 0.12 & \pm 0.21 & 26 \\
\hline EAB & 0.00 & \pm 0.08 & 241 & $\mathrm{BCC}$ & -0.15 & \pm 0.32 & 10 & LHO & -0.09 & \pm 0.12 & 90 \\
\hline EAU & -0.06 & \pm 0.09 & 158 & BDL & 0.08 & \pm 0.11 & 83 & WPM & -0.04 & \pm 0.13 & 81 \\
\hline $\mathrm{EBH}$ & -0.06 & \pm 0.10 & 225 & $\mathrm{BHH}$ & -0.05 & \pm 0.10 & 114 & CWF & -0.06 & \pm 0.10 & 133 \\
\hline EBL & 0.13 & \pm 0.12 & 82 & BNA & -0.27 & \pm 0.12 & 70 & $\mathrm{KBI}$ & 0.00 & \pm 0.10 & 120 \\
\hline EDI & -0.36 & \pm 0.09 & 175 & BTA & 0.11 & \pm 0.11 & 84 & KEY & 0.13 & \pm 0.25 & 17 \\
\hline EDR & 0.05 & \pm 0.28 & 12 & BWH & 0.02 & \pm 0.11 & 99 & KSY & 0.08 & \pm 0.14 & 55 \\
\hline EDU & 0.21 & \pm 0.12 & 74 & CDU & -0.03 & \pm 0.12 & 73 & KUF & 0.09 & \pm 0.21 & 25 \\
\hline ELO & -0.03 & \pm 0.09 & 214 & CKE & -0.11 & \pm 0.13 & 61 & KWE & -0.05 & \pm 0.09 & 151 \\
\hline ESK & -0.46 & \pm 0.25 & 17 & CSF & -0.02 & \pm 0.13 & 65 & SBD & -0.19 & \pm 0.10 & 136 \\
\hline ESY & 0.24 & \pm 0.17 & 36 & EAU & 0.17 & \pm 0.10 & 162 & $\mathrm{MCH}$ & -0.16 & \pm 0.12 & 96 \\
\hline GAL & -0.16 & \pm 0.26 & 17 & EBL & 0.19 & \pm 0.10 & 140 & HAE & -0.15 & \pm 0.12 & 94 \\
\hline GCL & -0.16 & \pm 0.22 & 21 & ECK & -0.17 & \pm 0.11 & 89 & HLM & -0.23 & \pm 0.10 & 120 \\
\hline GMK & -0.04 & \pm 0.18 & 29 & EDI & -0.08 & \pm 0.10 & 160 & SSP & -0.09 & \pm 0.10 & 143 \\
\hline $\mathrm{KAC}$ & -0.06 & \pm 0.11 & 101 & ESK & -0.20 & \pm 0.10 & 102 & SWN & 0.48 & \pm 0.27 & 17 \\
\hline KAR & 0.08 & \pm 0.11 & 102 & ESY & 0.38 & \pm 0.14 & 65 & SSW & 0.18 & \pm 0.26 & 16 \\
\hline KNR & -0.06 & \pm 0.16 & 40 & GAL & 0.12 & \pm 0.13 & 63 & & & & \\
\hline $\mathrm{KPL}$ & 0.14 & \pm 0.10 & 129 & GCD & -0.27 & \pm 0.12 & 76 & & & & \\
\hline $\mathrm{KSB}$ & 0.02 & \pm 0.10 & 115 & $\mathrm{GCL}$ & -0.08 & \pm 0.17 & 43 & & & & \\
\hline KSK & 0.36 & \pm 0.18 & 32 & GMK & 0.16 & \pm 0.16 & 48 & & & & \\
\hline MCD & 0.07 & \pm 0.15 & 52 & LMI & 0.11 & \pm 0.13 & 64 & & & & \\
\hline MDO & 0.05 & \pm 0.12 & 69 & LRN & 0.08 & \pm 0.19 & 30 & & & & \\
\hline MME & -0.13 & \pm 0.21 & 24 & PCA & -0.07 & \pm 0.13 & 72 & & & & \\
\hline $\mathrm{MVH}$ & 0.16 & \pm 0.18 & 32 & PCO & -0.11 & \pm 0.11 & 128 & & & & \\
\hline PCA & 0.07 & \pm 0.12 & 85 & PGB & -0.07 & \pm 0.15 & 55 & & & & \\
\hline PCO & -0.17 & \pm 0.09 & 195 & PMS & 0.08 & \pm 0.13 & 81 & & & & \\
\hline PGB & 0.10 & \pm 0.13 & 60 & POB & 0.29 & \pm 0.31 & 11 & & & & \\
\hline PMS & 0.01 & \pm 0.11 & 82 & XAL & -0.01 & \pm 0.15 & 47 & & & & \\
\hline
\end{tabular}

Central England

\section{Borders}

Term

Term

BH

BHr

BA




$\begin{array}{llllllll}\text { POB } & 0.13 & \pm 0.26 & 14 & \text { XDE } & 0.00 & \pm 0.12 & 71 \\ \text { REB } & -0.02 & \pm 0.20 & 25 & \text { XSO } & 0.08 & \pm 0.16 & 41 \\ \text { RRH } & -0.08 & \pm 0.21 & 24 & & & & \\ \text { RRR } & -0.09 & \pm 0.16 & 42 & & & & \\ \text { RSC } & -0.02 & \pm 0.24 & 17 & & & & \\ \text { RTO } & 0.19 & \pm 0.25 & 16 & & & & \end{array}$




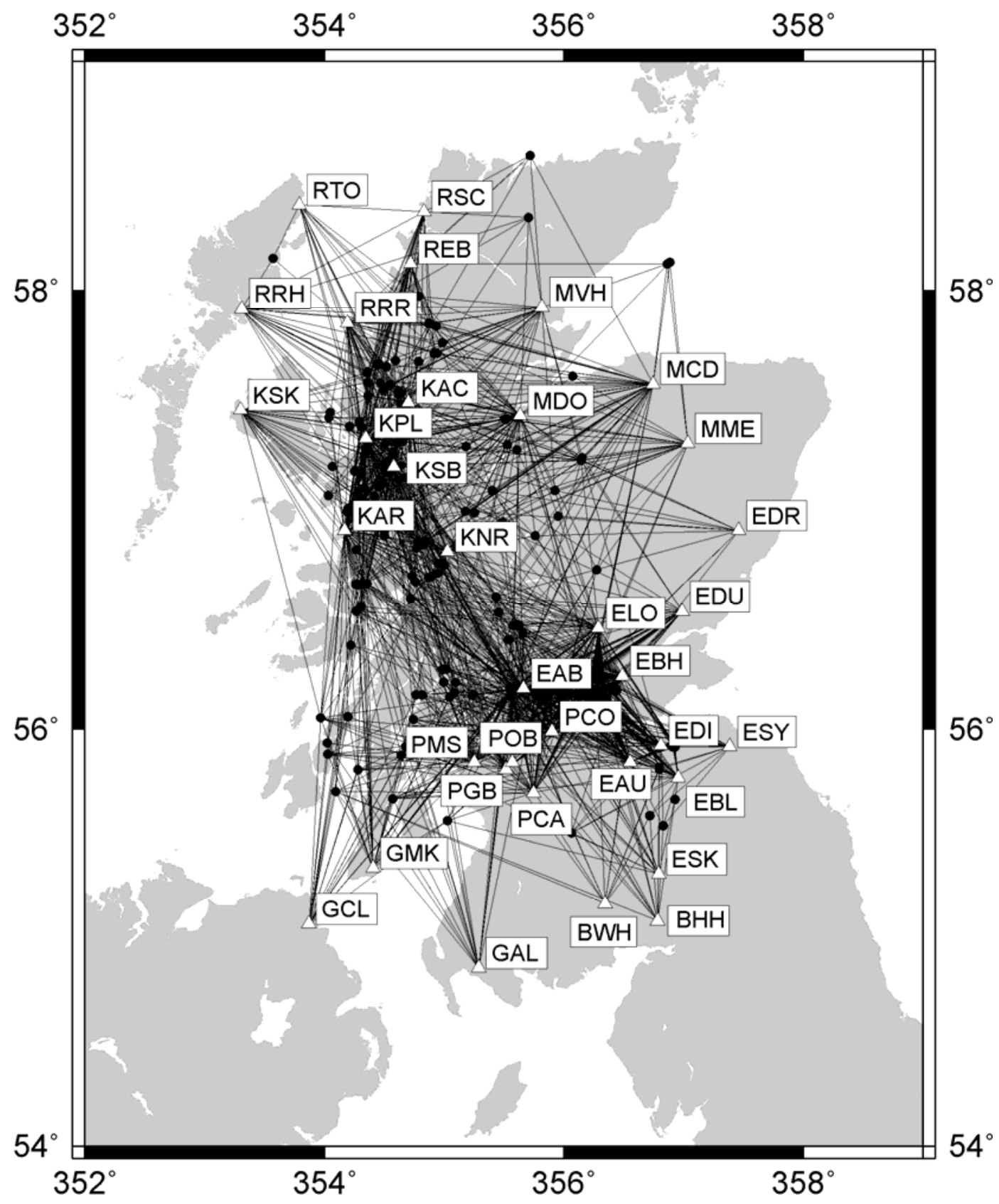

Figure 1(a). Map showing propagation paths between earthquakes (black dots) and UK seismometer stations (triangles), corresponding to the seismograms used in the analysis of variance study for Central and West Scotland. 




Figure 1(b). As for Figure 1(a), for the Border region. 


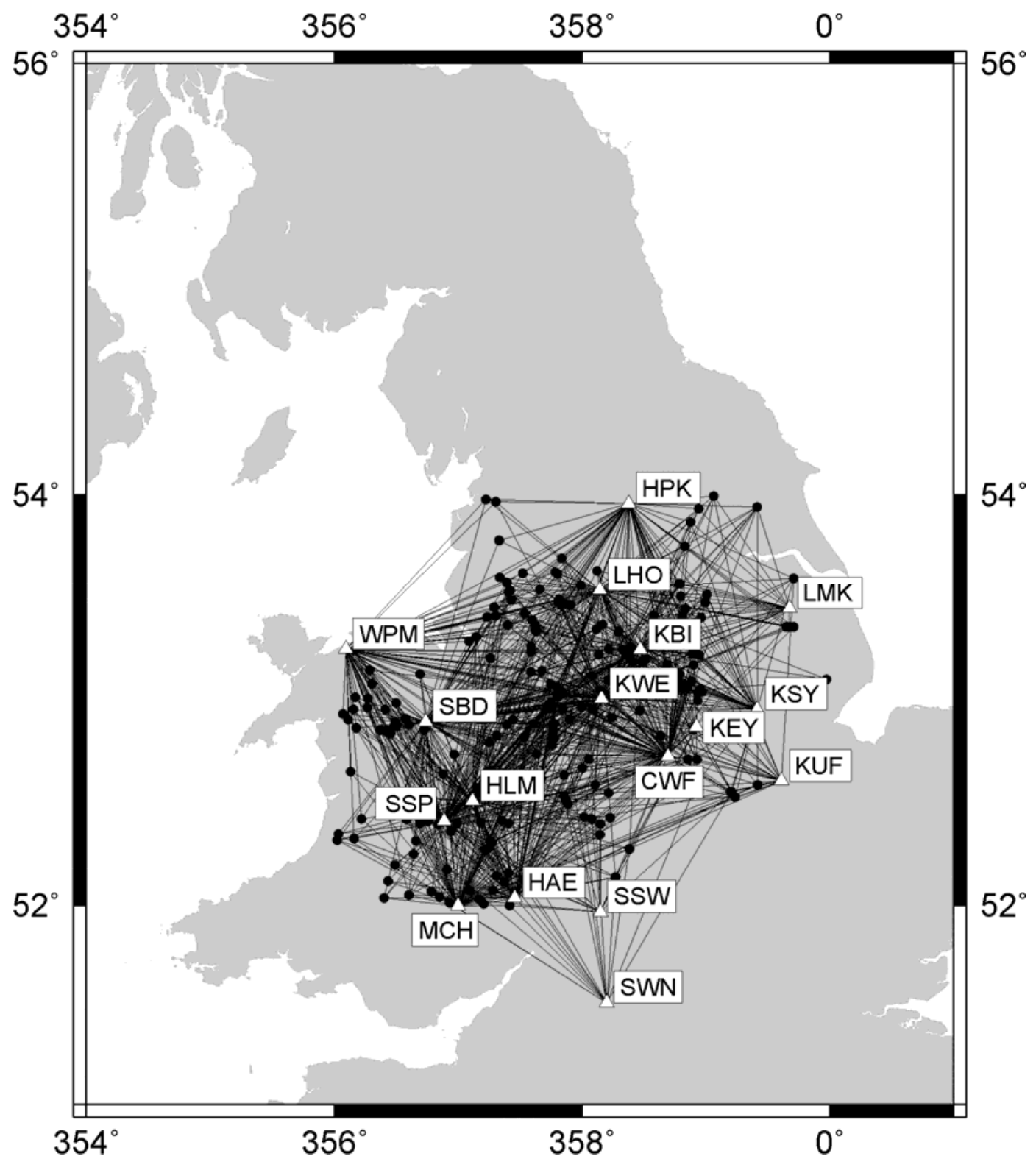

Figure 1(c). As for Figure 1(a), for Central England. 


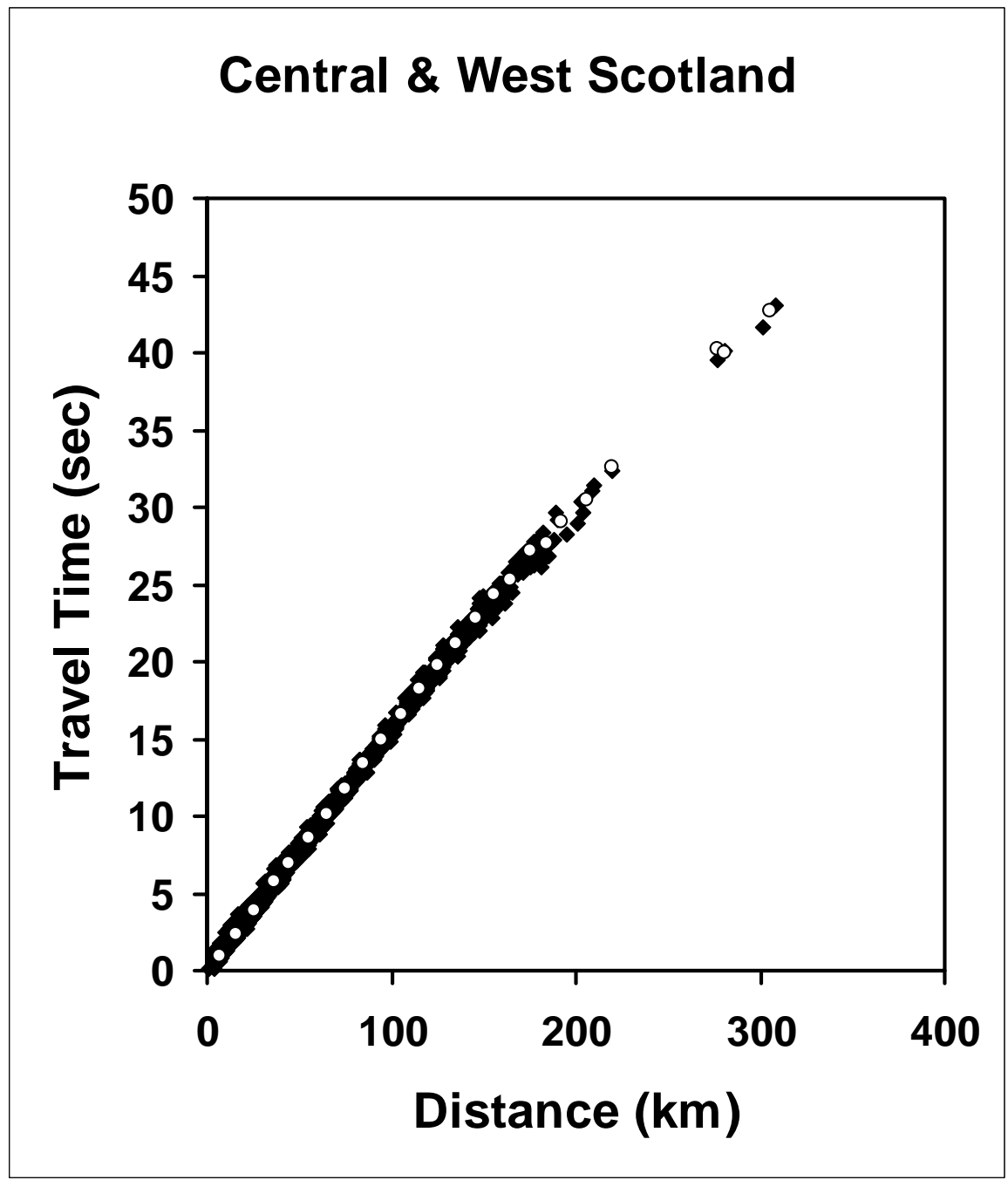

Figure 2(a). Distance terms (open circles) obtained from analysis of variance of observed P-wave travel times from bulletin data (black diamonds) for propagation paths in Central and West Scotland. 


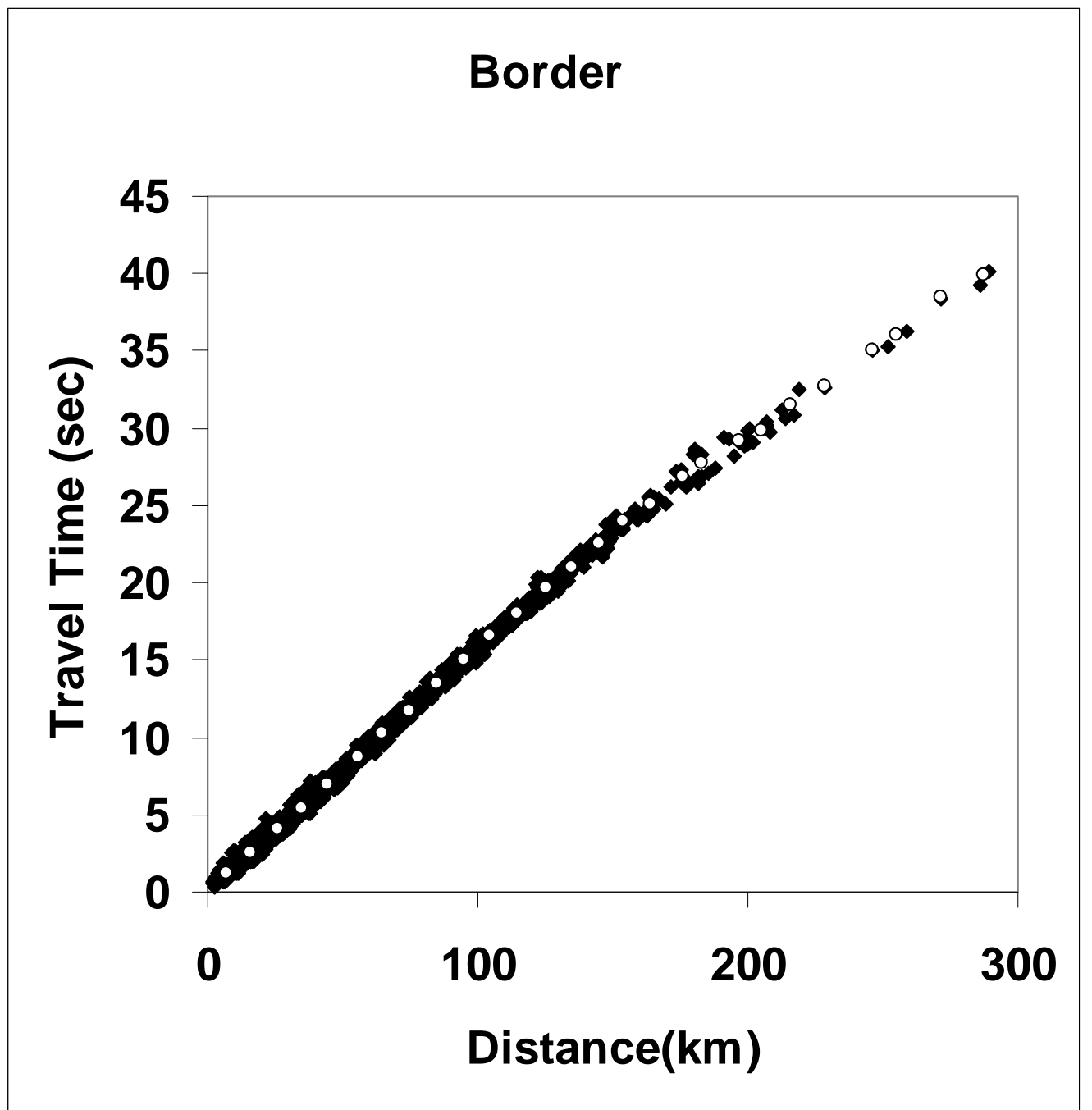

Figure 2(b). As Figure 2(a), for recorded P-wave travel times in the Border region from earthquakes shown in Figure 1(b). 


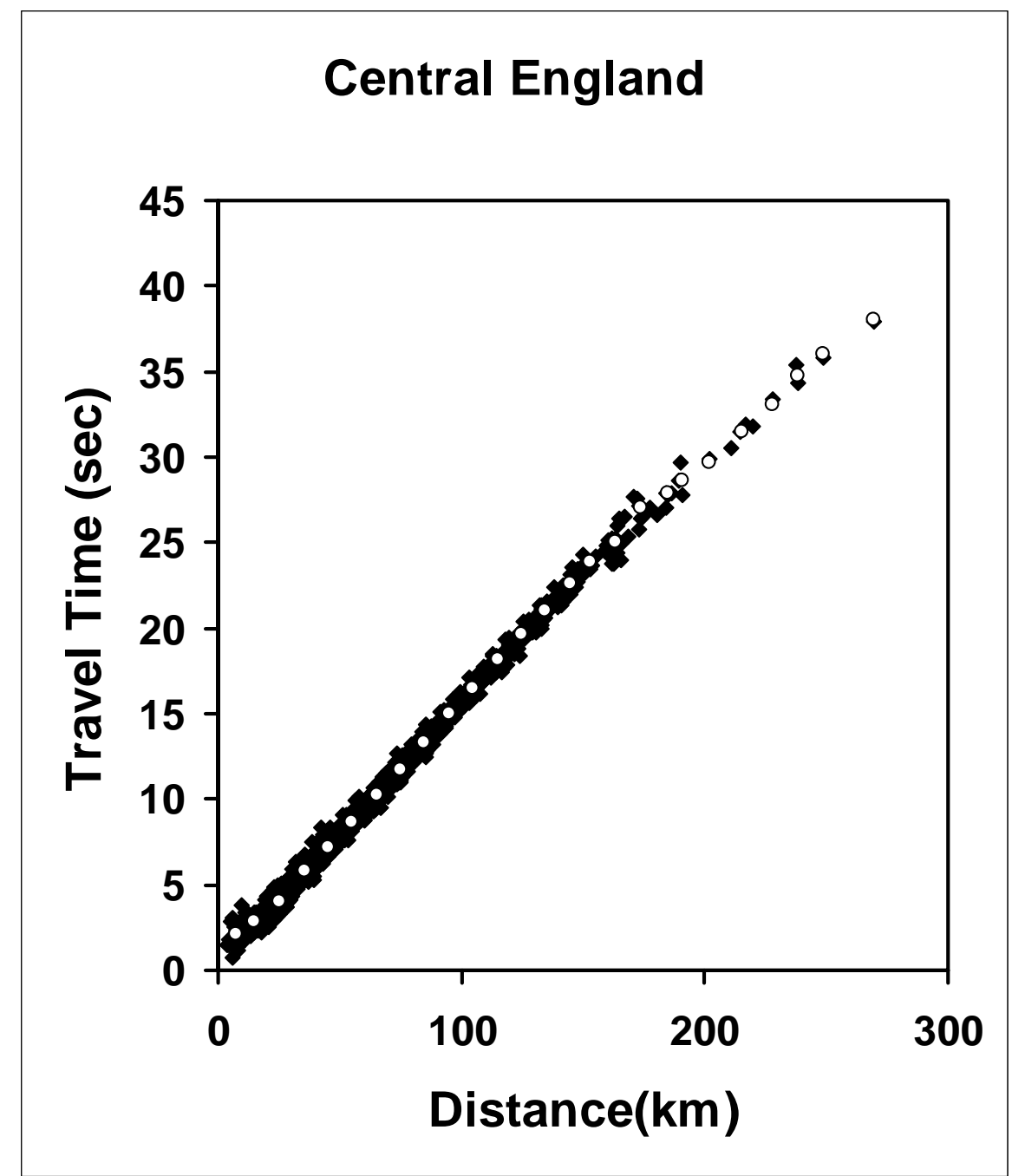

Figure 2(c). As Figure 2(a), for recorded P-wave travel-times in Central England from earthquakes shown in Figure 1(c). 


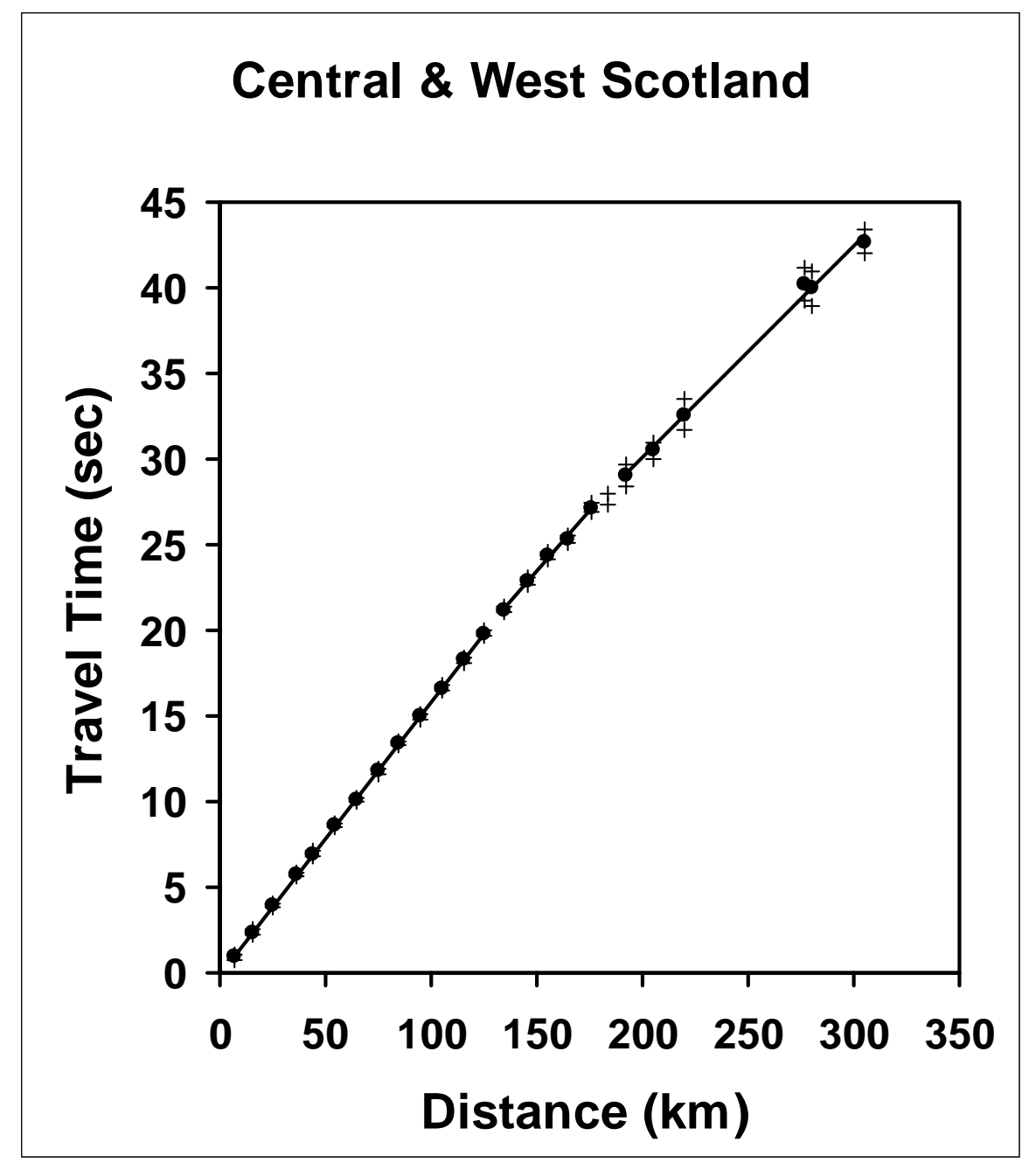

Figure 3(a). Distance terms obtained from analysis of variance of $\mathrm{P}$-wave travel times for propagation paths in Central and West Scotland, showing 95\% confidence limits (crosses) and observed linear trendlines. 


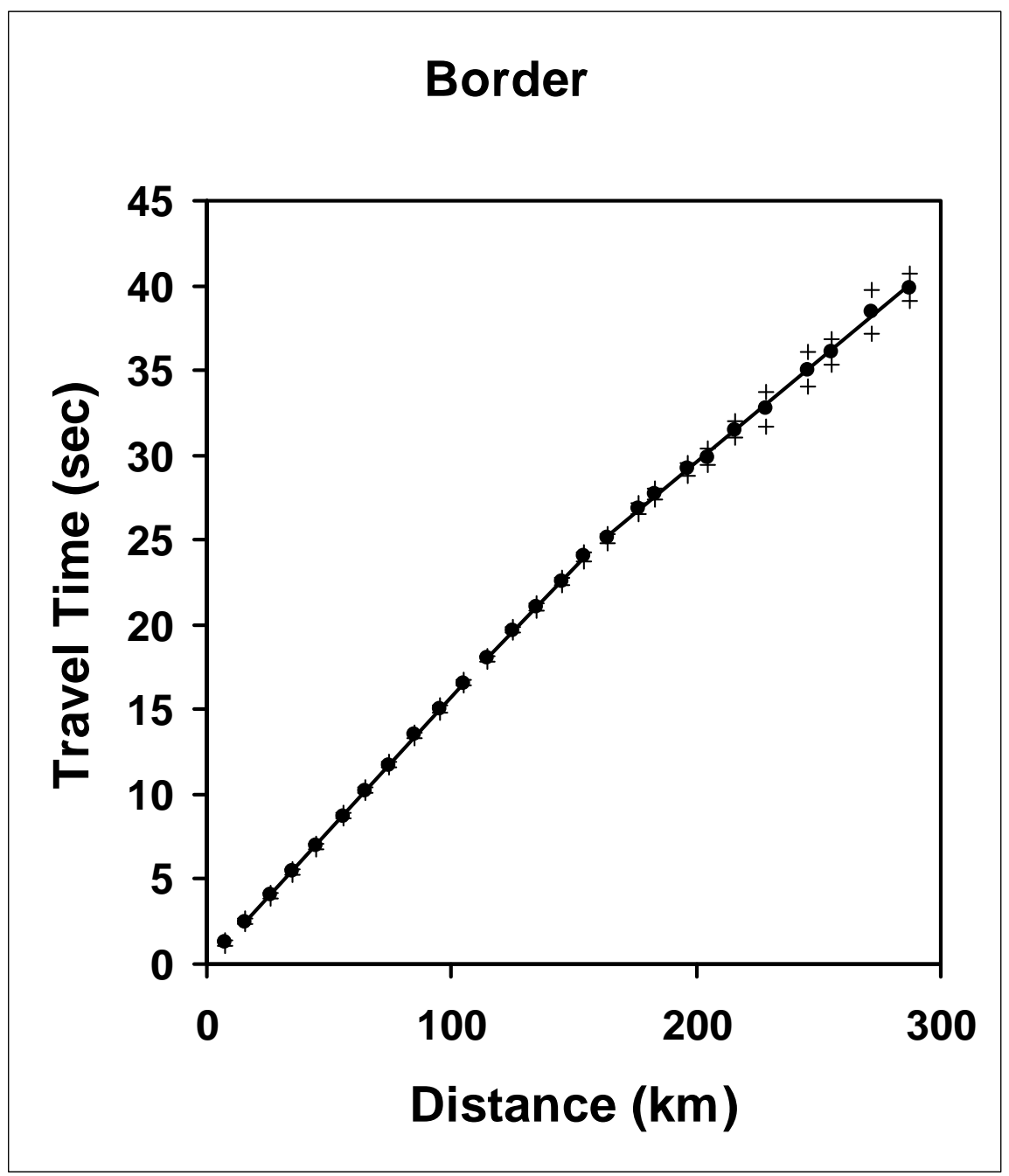

Figure 3(b). Distance terms obtained from analysis of variance of $\mathrm{P}$-wave travel times for propagation paths in the Border region, showing 95\% confidence limits (crosses) and observed linear trendlines. 


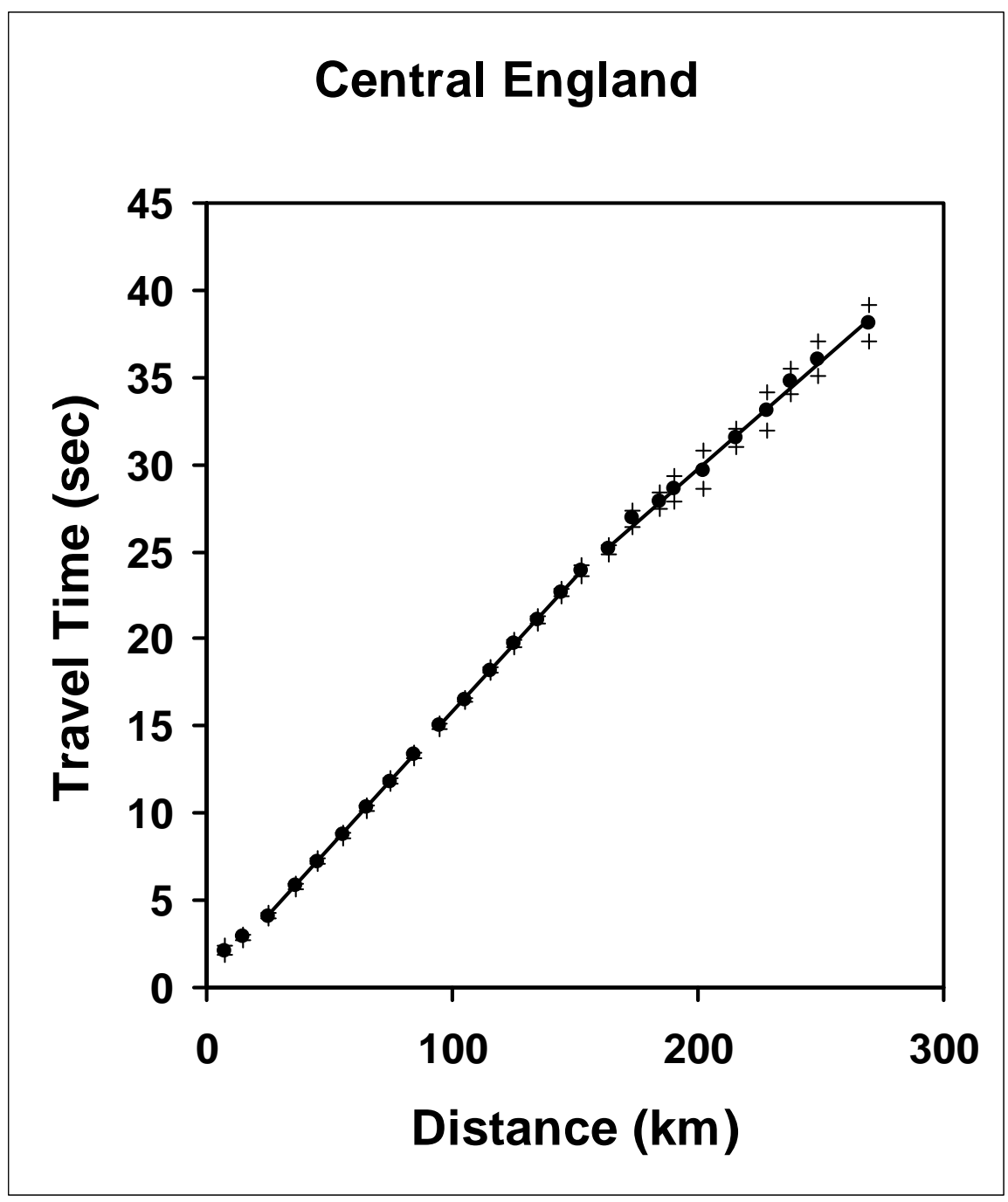

Figure 3(c). Distance terms obtained from analysis of variance of P-wave travel times for propagation paths in Central England, showing 95\% confidence limits (crosses) and observed linear trendlines. 




Figure 4. The resulting 1-D velocity-depth models for Central \& West Scotland, Border, and Central England regions, compared with the two-layer model used for earthquake location. 